\title{
Association of the rs4646994 in ACE gene with susceptibility to tuberculosis in a region of the Brazilian Amazon
}

Débora Chistina Ricardo Fernandes Porchera

Universidade Federal do Pará

Ana Cristina Oliveira Braga

Universidade Federal do Pará

Diana Feio Veiga Borges Leal

Universidade Federal do Pará

Pablo Diego Carmo Pinto

Universidade Federal do Pará

Mayara Natália Santana da Silva

Universidade Federal do Pará

Lucas Cauê Bezerra Santos

Universidade Federal do Pará

Cintia Helena Braga da Silva

Universidade Federal do Pará

Giovana Escribano Costa

Universidade Federal do Pará

Maria Clara Costa Barros

Universidade Federal do Pará

Cleonardo Augusto Silva

Universidade Federal do Pará

Paulo Pimentel Assumpção

Universidade Federal do Pará

Ândrea Ribeiro Santos

Universidade Federal do Pará

Sidney Emanuel Batista dos Santos

Universidade Federal do Pará

Marianne Rodrigues Fernandes

Universidade Federal do Pará

Ney Pereira Carneiro dos Santos ( $\nabla$ npcsantos.ufpa@gmail.com )

Universidade Federal do Pará 


\section{Research Article}

Keywords: Tuberculosis, Susceptibility, INDEL, Polymorphisms, ACE.

Posted Date: May 10th, 2021

DOl: https://doi.org/10.21203/rs.3.rs-473237/v1

License: (c) (i) This work is licensed under a Creative Commons Attribution 4.0 International License. Read Full License 


\section{Abstract}

Background: Tuberculosis is a global public health issue. Recent studies suggested association of host genetic factors to tuberculosis susceptibility in many populations. Polymorphisms can influence the host immune responses to tuberculosis. This study was designed to investigate the association of seventeen genetic polymorphisms with susceptibility and severity to tuberculosis in a sample of Brazilian population.

Methods: This case-control study encompassed 283 active tuberculosis patients and 145 healthy subjects that had contact with the bacillus. Genotyping of 13 INDELs polymorphisms and 4 SNPs was achieved using Multiplex PCR method and TaqMan SNP Genotyping Assays.

Results: Of the 17 investigated markers, only the ACE marker (rs4646994) showed significant differences between cases and controls.

Conclusions: The DEL/DEL (deletion / deletion) genotype of the ACE marker configured a protection factor for the development of tuberculosis. As there is no data in the recent literature relating this polymorphism with tuberculosis in a Brazilian population, our study has become unprecedented.

\section{Background}

Tuberculosis is a public health problem despite the existence of international control programs. About 10 million cases occurred worldwide and eventually 2-3 million die of the disease every year according to World Health Organization (WHO). Nearly one-quarter of the world population is estimated to be infected with Mycobacterium tuberculosis (Mtb) in 2020, the pathogen responsible for TB disease in humans, but only $5-15 \%$ of these people will fall ill with active TB disease [1-3].

The M. tuberculosis is not the only determining factor toward disease progression. Currently, there is an increasing focus in genomic research of human. Genetic factors play a major role in the pathogenesis and polymorphisms in the different genes can influence and modulate the immune responses [4]. Genetic polymorphisms, such as single nucleotide polymorphisms (SNPs) and insertion/deletion (INDELs) can affect gene transcription, mRNA processing, levels of cytokine production and gene expression $[5,6]$.

INDELs variation at protein-coding genes and in other functionally constrained regions of the genome is likely to form the main genetic background to phenotypic variation, possibily causing diseases like cancer, tuberculosis and Alzheimer's disease [7-9]. Many studies have suggested that polymorphisms in immune response genes such as interleukins $[10-12]$ and $C C R 5[13,14]$, apoptotic pathways such as TP53 [15] and metabolism such as UGT1A1 are associated with TB among different populations [16, 17].

Micrornas (miRNA) plays an important role in regulating many biological pathways, such as innate immune response against various infections. recently, mirna have been studied as new potentials diagnostic biomarkers that are involved in several cases such as cancer, autoimmune disease and many 
infectious diseases, including tuberculosis [18-28]. SNPs variants such as rs3746444 in miR-499, rs1799782 in miR-138 and rs1799782 in miR-146a may influence the pattern of gene expression related to the immune response and consequently influence in the genetics of different infectious diseases [22, $27,29-31]$.

The bacillus M. tuberculosis is present worldwide and most of the people who fall ill with TB live in lowand middle-income countries. In the Americas, incidence is slowly increasing, particularly an upward trend in Brazil [32]. Brazilian population genetic structure reveals a high degree of admixture [33] due to this fact it is important in case studies and control to perform genomic control of ancestrality [34-38].

In this study, we aimed to investigate the association of INDEL and SNPS variants for the susceptibility of $\mathrm{Tb}$ in an Amazon region with a high degree of interethnic admixture.

\section{Methods}

\section{Subjects}

A cohort of 428 participants were recruited: patients with active pulmonary TB $(n=283)$ and healthy controls without tuberculosis infection $(n=145)$. The subjects investigated were from the Hospital Universitário João de Barros Barreto in Brazil. Eligibility criteria for TB patients included: 1) $\geq 18$-year-old; 2) diagnosis of TB based on sputum smear examinations for acid-fast bacilli and/or the culture of $M$. tuberculosis, 3) started treatment until 6 months to signal and symptoms appareled. Control subjects were asymptomatic hospital volunteers with contact of bacteria-confirmed active TB patients, attending hospital for annual physical examination and no history of TB. Individuals from control group who contracted the tuberculosis disease were excluded from the study. Personal information was collected from a questionnaire including age, gender, comorbidities (cancer, diabetes, non-drug hepatitis and autoimmune disease - type 1 diabetes and rheumatoid arthritis), socioeconomic level and smoking habits.

\section{Ethical approval}

All protocols were approved by the João Barros Barreto Hospital ethics committee and the written informed consent was obtained from all participants involved in this study (protocol $n^{\circ} 350507$ ).

\section{Genotyping of selected polymorphisms}

It was chosen seventeen representative genetic markers involved in different stages of the immune response (Additional file 1). Genomic DNA was isolated from peripheral blood leukocytes using phenol extraction method [39].

Four SNPs were genotyped using TaqMan ${ }^{\circledR}$ SNP Genotyping Assays (Applied Biosystems, Foster City, USA). Thirteen INDELs polymorphisms were genotyped by a single multiplex reaction with Master Mix QIAGEN® Multiplex PCR kit (Qiagen, Hilden, Germany) and the primers. Multiplex PCR products were 
separated and analyzed by capillary electrophoresis on the ABI 3130 Genetic Analyzer instrument (Applied Biosystems), using GS-500 LIX as pattern of molecular weight (Applied Biosystems), G5 virtual filter matrix and POP7 (Applied Biosystems). After data collect, samples were analyzed in GeneMapper®3.7 software (Applied Biosystems).

\section{Ancestry}

Genetic admixture in the Brazilian samples were estimated using a set of 61 autosomal ancestry informative markers (AIMs). The protocol used was previously described by Santos et al. 2010 and Ramos et al [40,41]. It was performed to estimate the mean contributions of European, African, and Native American ancestries to the Brazilian samples, using the STRUCTURE 2.3.3 software [42-44].

\section{Statistical analyses}

Statistical analyses were performed using the RStudio v.1.3 software. Group comparisons for categorical variables were performed using the chi-squared test, whilst the t-Student test was used to analyze the continuous variables. Multiple logistic regression analyses were performed to estimate the odds ratio (OR) with $95 \%$ confidence intervals $(\mathrm{Cl})$. Only the covariates that were significant (gender, comorbidities, smoking, ancestrality genetics - African, European and Amerindian) were included in the logistic regression analysis. A 5\% significance level was used for the analyses. Deviation from Hardy-Weinberg equilibrium was assessed using chi-squared tests with Bonferroni correction. The results were analyzed comparing the genotypic distributions adopting the recessive and dominant model and they estimated values of $p$ corrected for multiple tests through FDR (False Discovery Rate) test.

\section{Results}

The data of clinical and demographic distribution of tuberculosis patients and healthy individuals is shown in Table 1. The significant variables between the case and control groups were: The male patients were more frequent among tuberculosis patients (47.7\%). In relation to comorbidity, the case group had higher rate than the control group (35.8\%). Regarding smoking, among the patients the proportion of smoker was higher than in the control group (31.7\%). Analysis of ethnicity showed that the mean frequency of Amerindian was higher among tuberculosis patients (0.336) and Europeans were more frequent in healthy individuals (0.496), there is also a significative difference of Africans but smaller than the others (0.253). Due to the great stratification of the Brazilian population, particularly the northern population, ancestry will be used as a confounding variable in risk analyzes.

Table 1: Demographic and clinical characteristics of the sample of patients with tuberculosis and of the control group without active tuberculosis. 
TUBERCULOSIS

$\begin{array}{lll}\text { VARIABLES } & \mathrm{n}=283(\%) & \text { CONTROL } \\ & \mathrm{n}=145(\%) & p \text { VALUE }\end{array}$

\begin{tabular}{|c|c|c|c|}
\hline Age, years ${ }^{t}$ & $50 \pm 16.84$ & $52 \pm 9.15$ & 0.210 \\
\hline Gender $^{\mathrm{b}}(\mathrm{M} / \mathrm{F})$ & $116(47.7 \%) / 127$ (52.2\%) & $25(17.3 \%) / 120$ (82.7\%) & $3.6 \mathrm{E}^{-9}$ \\
\hline Comorbidities ${ }^{b}$ & $107(35.8 \%)$ & $67(46.2 \%)$ & 0.021 \\
\hline Smoking (Yes) ${ }^{b}$ & $77(31.7 \%)$ & $30(20.7 \%)$ & 0.002 \\
\hline \multicolumn{4}{|c|}{${ }^{\mathrm{C}}$ Ancestrality Genetics } \\
\hline African & $0.253 \pm 0.12$ & $0.215 \pm 0.11$ & 0.0002 \\
\hline European & $0.409 \pm 0.13$ & $0.496 \pm 0.16$ & $5.7 \mathrm{E}^{-9}$ \\
\hline Amerindian & $0.336 \pm 0.13$ & $0.289 \pm 0.14$ & 0.00004 \\
\hline
\end{tabular}

${ }^{t}$-Test Student T; ${ }^{\mathrm{b}}$ Fisher's Exact Test; ${ }^{\mathrm{c}}$ Mann Whitney Test; Data are shown as mean + standard deviation.

The data obtained demonstrate that the polymorphisms investigated in the groups (patients and controls) had the genotypic distribution as predicted by the Hardy-Weinberg equilibrium. The findings present (table 2) the allelic and genotypic distribution relative to the 13 INDEL-type polymorphisms and the 4 SNPs investigated between the patient groups and the control group of the sample and the odds ratio (OR) among the groups analyzed.

Table 2: Association between groups for the 17 polymorphisms investigated. 


\section{PATIENTS CONTROLS $p^{c} \quad$ OR (95\% CI ) ${ }^{\mathrm{d}}$ \\ n (\%) n (\%)}

IL1A (rs3783553)

INS / INS

INS / DEL

DEL / DEL

INS

DEL

TYMS (rs151264360)

INS / INS

INS / DEL

DEL / DEL

INS

DEL

UGT1A1 (rs8175347)

INS / INS

INS / DEL

DEL / DEL

INS

DEL

CYP2A1 (rs17880560)

INS / INS

INS / DEL

DEL / DEL

INS

DEL

SGSM03 (rs56228771)

INS / INS

INS / DEL

DEL / DEL

INS

DEL

IL4 (rs79071878)

INS / INS

INS / DEL

DEL / DEL

INS

DEL

MDM2 (rs3730485)

INS / INS

INS / DEL

DEL / DEL

INS

DEL

ACE (rs4646994)

INS / INS

INS / DEL

DEL / DEL

INS

DEL

CCR5 (rs333)

INS / INS

INS / DEL

DEL / DEL

$\begin{array}{llllll}64(23.2 \%) & 30 & (20.7 \%) & & \\ 128(46.4 \%) & 70 & (48.3 \%) & 0.844 & 0.934 & (0.472-1.847) \\ 84(30.4 \%) & 45 & (31.0 \%) & & \\ 0.46 & 0.45 & & & \\ 0.54 & 0.55 & & & \end{array}$

$53(19.2 \%) \quad 14(09.7 \%)$

$120(43.5 \%) \quad 66(45.5 \%) \quad 0.202 \quad 1.719(0.78-3.950)$

$103(37.3 \%) \quad 65(44.8 \%)$

$0.41 \quad 0.32$

$0.59 \quad 0.68$

$116(42.6 \%) \quad 65(46.1 \%)$

$115(42.3 \%) \quad 55(39.0 \%) \quad 0,132 \quad 0.978(0.950-1.007)$

$41 \quad(15.1 \%) \quad 21(14.9 \%)$

$0.64 \quad 0.66$

$0.36 \quad 0.34$

$241(86.3 \%) \quad 120(82.8 \%)$

$\begin{array}{lllllll}37 & (13.3 \%) & 25 & (17.2 \%) & 0.101 & 1.842 & (0.887-3.825)\end{array}$

$1 \quad(0.40 \%) \quad 0 \quad(0 \%)$

$0.93 \quad 0.91$

$0.07 \quad 0.09$

$\begin{array}{lllll}108(39.1 \%) & 74(51.0 \%) & & \\ 122(44.2 \%) & 57(39.3 \%) & 0.326 & 0.752(0.427-1.327) \\ 46(16.7 \%) & 14(9.7 \%) & & \\ 0.61 & 0.71 & & \\ 0.39 & 0.29 & & \end{array}$

$43(15.6 \%) \quad 21(14.5 \%)$

$133(48.2 \%) \quad 68(46.9 \%) \quad 0.631 \quad 0.829(0.384-1.786)$

$100(36.2 \%) \quad 56(38.6 \%)$

$0.4 \quad 0.38$

$0.6 \quad 0.62$

$18(6.5 \%) \quad 11(7.6 \%)$

$122(44.2 \%) \quad 58(40.0 \%) \quad 0,174 \quad 0.457(0.148-1.412)$

$136(49.3 \%) \quad 76(52.4 \%)$

$0.29 \quad 0.23$

$0.71 \quad 0.72$

$17 \quad(6.0 \%) \quad 11(7.6 \%)$

$120(42.4 \%) \quad 49(33.8 \%) \quad 0.005 \quad 0.465(0.272-0.794)$

$146(51.6 \%) \quad 85(58.6 \%)$

$0.27 \quad 0.25$

$0.73 \quad 0.75$

$1 \quad(0.4 \%) \quad 0 \quad(0.0 \%)$

$18(6.5 \%) \quad 15 \quad(10.3 \%) \quad 0.413 \quad 0.680(0.270-1.712)$

$257(93.1 \%) \quad 130(89.7 \%)$ 


\begin{tabular}{|c|c|c|c|c|}
\hline INS & 0.03 & 0.05 & & \\
\hline \multirow{2}{*}{\multicolumn{5}{|c|}{$\begin{array}{l}\mathrm{DEL} \\
\text { UCP2 (no rs) }\end{array}$}} \\
\hline & & & \\
\hline INS / INS & $131(47.5 \%)$ & 74 (51.0\%) & & \\
\hline INS / DEL & $113(40.9 \%)$ & $57(39.3 \%)$ & 0.361 & $0.774(0.447-1.340)$ \\
\hline DEL / DEL & 32 (11.6\%) & 14 (9.7\%) & & \\
\hline INS & 0.68 & 0.71 & & \\
\hline DEL & 0.32 & 0.29 & & \\
\hline \multicolumn{5}{|l|}{$H L A-G($ rs371194629) } \\
\hline INS / INS & $77 \quad(26.0 \%)$ & $49(33.8 \%)$ & & \\
\hline INS / DEL & $144(48.6 \%)$ & $72(49.6 \%)$ & 0,635 & $0.866(0.478-1.568)$ \\
\hline DEL / DEL & $75 \quad(25.3 \%)$ & 24 (16.6\%) & & \\
\hline INS & 0.44 & 0.58 & & \\
\hline DEL & 0.56 & 0.41 & & \\
\hline \multicolumn{5}{|l|}{ XRCC1 (rs3213239) } \\
\hline INS / INS & $13(7.4 \%)$ & $10(6.9 \%)$ & & \\
\hline INS / DEL & $88 \quad(50.0 \%)$ & $56(38.6 \%)$ & 0.109 & $0.390(0.123-1.234)$ \\
\hline DEL / DEL & $175(42.6 \%)$ & $79(54.5 \%)$ & & \\
\hline INS & 0.21 & 0.26 & & \\
\hline DEL & 0.79 & 0.74 & & \\
\hline \multicolumn{5}{|l|}{ TP53 (rs1 7880560) } \\
\hline INS / INS & $196(71.0 \%)$ & $101(69.7 \%)$ & & \\
\hline INS / DEL & $74 \quad(26.8 \%)$ & $42 \quad(29.0 \%)$ & 0.610 & $1.64(0.649-2.087)$ \\
\hline DEL / DEL & $6 \quad(2.2 \%)$ & $2 \quad(1.4 \%)$ & & \\
\hline INS & 0.84 & 0.84 & & \\
\hline DEL & 0.16 & 0.16 & & \\
\hline \multicolumn{5}{|l|}{$m i R-146 A(r s 2910164)$} \\
\hline $\mathrm{CC}$ & $128(46.6 \%)$ & $67(47.9 \%)$ & & \\
\hline $\mathrm{GC}$ & $123(44.7 \%)$ & $57(40.7 \%)$ & 0.256 & $1.753(0.666-4.617)$ \\
\hline GG & $24 \quad(8.7 \%)$ & $16(11.4 \%)$ & & \\
\hline $\mathrm{C}$ & 0.69 & 0.68 & & \\
\hline G & 0.31 & 0.32 & & \\
\hline \multicolumn{5}{|l|}{ miR-192A (rs11614913) } \\
\hline TT & $23(8.4 \%)$ & $9 \quad(6.7 \%)$ & & \\
\hline CT & $119(43.4 \%)$ & $55(40.7 \%)$ & 0.113 & $1.578(0.888-2.773)$ \\
\hline $\mathrm{CC}$ & $132(48.2 \%)$ & $71(52.6 \%)$ & & \\
\hline $\mathrm{T}$ & 0.3 & 0.27 & & \\
\hline $\mathrm{C}$ & 0.7 & 0.73 & & \\
\hline \multicolumn{5}{|l|}{ miR-499 (rs3746444) } \\
\hline GG & $21(7.4 \%)$ & $10(6.9 \%)$ & & \\
\hline GA & $111(39.2 \%)$ & $55(37.9 \%)$ & 0.166 & $0.717(0.447-1.149)$ \\
\hline AA & 151 (53.4\%) & $80(55.2 \%)$ & & \\
\hline $\mathrm{G}$ & 0.27 & 0.26 & & \\
\hline & 0.73 & 0.74 & & \\
\hline \multicolumn{5}{|l|}{ miR-149 (rs2292832) } \\
\hline $\mathrm{CC}$ & $36 \quad(13.2 \%)$ & $19(13.2 \%)$ & & \\
\hline TC & $115(42.3 \%)$ & $66(45.8 \%)$ & 0.206 & $0.639(0.320-1.279)$ \\
\hline TT & $121(44.5 \%)$ & $59(41.0 \%)$ & & \\
\hline $\mathrm{C}$ & 0.34 & 0.36 & & \\
\hline $\mathrm{T}$ & 0.65 & 0.63 & & \\
\hline
\end{tabular}

c p-value obtained by regression age-adjusted logistics, gender, comorbidity, smoking, and genetic ancestry. Adopting the dominant model. The $\mathrm{p}$ values were corrected for FDR multiple test; ${ }^{\mathrm{d}}$ Adjusted Odds Ratio (OR). 
When it was investigated INDELS and SNPs polymorphisms, only the DEL/DEL genotype of the $A C E$ variant (rs4646994) showed significant relative risk between cases and controls ( $O R=0.465 ; p=0.005)$. The analysis of this marker showed that in the dominance test (DEL / DEL genotype vs INS / DEL + INS / INS), there was a greater proportion of homozygous individuals DEL / DEL among the control subjects $(51,6 \%)$ compared to the patients $(51,6 \%)$. The Odds Ratio of 0.465 indicates protective effect in individuals with DEL/DEL genotype in relation to the control group.

\section{Discussion}

TB is a complex disease, and it is known that the host and pathogen factors are related to the severity in the TB pathogenesis $[45,46]$. Several studies provide evidence that genetic factors play a major role in toward progression of TB, evidencing that polymorphisms in genes can influence and modulate the immune responses and this would be one of the reasons why infected people with Mtb are not progressing to TB disease $[28,37,47]$.

In this investigation, of the case-control type genetic association studies in admixed populations, ancestry-informative markers was used to detect population stratification. Ancestry related data showed significantly different contribution between groups for African, European and Native American ancestry. These results show a loss of European contribution and an increase of African and Native American contributions in pacient group with $\mathrm{Tb}$. A recent study of our group had already shown that there are differences between case and control groups about ancestry: the individuals with TB disease had significantly higher Amerindian ancestry and significantly lower European ancestry in Brazilian Amazon population [33].

Results showed that only the polymorphisms in the ACE gene were significant for the analysis of susceptibility to TB in the investigated groups regarded to the 17 genes investigated. We found DEL/DEL genotype of $A C E$ marker (rs4646994) showed significant association by setting up a protective factor for the development of tuberculosis. We sought to interpret these findings based on the genotype-dependent expression of this enzyme and on its ability to stimulate innate immunity from macrophages and neutrophils against mycobacteria[48] .

ACE has a role in both innate and adaptive responses by modulating macrophage and neutrophil function, effects that are due to increased $A C E$ activity [48-51]. Recent studies point to the functionality of $A C E$ in promoting the maturation of myelocytic lineage cells and to improve the effective phagocytosis capacity and consequent self-limitation of Mtb infection [52,53]. In this context, individuals with DEL/DEL genotype would have greater expression of the gene that would have a crucial role in the innate effective immune response, mainly because the control group was exposed to the bacillus without developing the disease.

Because of its role in immune response, the rs4646994 is mostly related with the susceptibility of diseases. A study also with an admixed population in Brazil shown that this polymorphism was associated with Colorectal Cancer risk and clinical features. It is also related with the progression of 
multiple myeloma in a Caucasian population and the development of moderate-sized adenocarcinomas and metastatic cancer in a Chinese population $[54,55]$.

Recent studies associated the DEL/DEL genotype with the risk of developing severe COVID-19 and increasing morbidities, this polymorphism also was associated with the progression of pneumonia in Severe Acute Respiratory Syndrome (SARS), corroborating its importance in the development of contagious infectious diseases [56-58].

There are few studies associating the DEL/DEL genotype with tuberculosis, yet Ogarkov and contributors in 2008, shown that this polymorphism was more frequently in male patients with tuberculosis in a Russian population, diverging from our results [59]. Also not consistent with our results, a study in a Chinese population demonstrated that the rs 4646994 was not a major etiological fator for tuberculosis [26].

\section{Conclusion}

From the data obtained in our study is possible to conclude that individuals with DEL/DEL genotype of the rs4646994 in ACE gene presented a $46 \%$ protective effect against the development of tuberculosis than individuals with other genotypes $(\mathrm{OR}=0,46)$. Nevertheless, as there are few studies with susceptibility to Tb in a Brazilian population, more studies are necessary with our population, once Brazil still remains among the 20 countries with more incidence of $\mathrm{Tb}$.

\section{List Of Abbreviations}

PB: base pair; ACE 2: angiotensin-converting-enzyme 2; AIMs: ancestry-informative markers; CCR5: chemokine receptor type 5,Cl: confidence intervals; CYP2E1: Cytochrome P450 2E1; DEL: deletion; FDR: False Descovery Rate; HLA-G: Human leukocyte antigen-G; IL1A: interleukin 1 alpha; IL4: interleukin 4; INDEL: insertion/ deletion; INS: insertion; MiR: miRNA or microRNA; MDM2: Mouse double minute 2 homolog; Mtb: Mycobacterium tuberculosis; NF-KB 1: Factor Nuclear Kappa B; OR: odds ratio; RNA: ribonucleic acid; SNP: Single nucleotide polymorphisms; SGSM03: Small protein G signaling modulator; TB: Tuberculosis; TGF- $\beta$ : Beta growth transformation factor; TP53: tumor protein $p 53 ;$ TYMS. thymidylate synthase; UCP2: mitochondrial uncoupling protein 2; UGT1A1: UDP Glucuronosyltransferase Family 1 Member A1; WHO: world health organization; XRCC1: X-ray repair cross-complementing protein 1.

\section{Declarations}

\section{Ethics approval and consent to participate}

The study protocol was approved by the João Barros Barreto Hospital ethic committee and followed the Declaration of Helsinki Ethical Principles for Medical Research Involving Human Subjects. The patients signed an informed consent before entering the study. 


\section{Consent for publication}

Not applicable.

\section{Availability of data and materials}

The datasets generated and analysed during the current study are available in the Figshare repository, https://figshare.com/s/0af7c9a15996be56a062.

\section{Competing interests}

The authors declare no conflict of interest.

\section{Funding}

This study was financed in part by the Coordenação de Aperfeiçoamento de Pessoal de Nível Superior Brasil (CAPES) and Conselho Nacional de Desenvolvimento Científico e Tecnológico - Brasil (CNPq). The funding source had no role in the design, data collection, analysis or interpretation of the study

\section{Authors' contributions}

DCRFP, DFVBL, MNSS, GEC and MCCB prepared the manuscript and interpreted the data; ACOB, CAS and PPA contributed for the data collection; PDCP, LCBS and PDCP conducted statistical analysis; PPA, ARS, SEBS, MRF and NPCS contributed to study design, reviewed and edited the manuscript. All authors have revisioned, read and approved the manuscript

\section{Acknowledgements}

The authors wish to thank all the participants of the study for their collaboration. This study was supported by the Brazilian National Research Council (CNPq), the Coordination for Higher Education Personnel Training (CAPES), the Amazonian Research Foundation (FAPESPA), and the Research and Extension faculties of the Federal University of Pará (PROPESP/PROEX/UFPA). None of these organizations had any role in the design of the study, collection or analysis of the data, the decision to publish the manuscript or its preparation. The contents of this study are the sole responsibility of the authors.

\section{References}

1. Daniel TM. The history of tuberculosis. Respir Med. 2006;100:1862-70.

2. Frothingham R, Stout JE, Hamilton CD. Current issues in global tuberculosis control. Int $\mathrm{J}$ Infect Dis. 2005;9:297-311.

3. WHO. Global tuberculosis report 2020. Geneva: World Health Organization; 2020. https://www.who.int/tb/publications/global_report/en/. Accessed 2 Nov 2020. 
4. Fernandes DCRO, Santos NPC, Moraes MR, Braga ACO, Silva CA, Ribeiro-dos-Santos A, et al. Association of the CYP2B6 gene with anti-tuberculosis drug-induced hepatotoxicity in a Brazilian Amazon population. Int J Infect Dis. 2015;33:28-31.

5. Pinto P, Salgado C, Santos NPC, Santos S, Ribeiro-dos-Santos Â. Influence of Genetic Ancestry on INDEL Markers of NFKB1, CASP8, PAR1, IL4 and CYP19A1 Genes in Leprosy Patients. PLOS Neglected Tropical Diseases. 2015;9:e0004050.

6. Li X, Li K, Wu Z. Association of four common SNPs in microRNA polymorphisms with the risk of hepatocellular carcinoma. Int J Clin Exp Pathol. 2015;8:9560-6.

7. Cavalcante GC, Freitas NDSDC, Ribeiro-Dos-Santos AM, De Carvalho DC, Da Silva EM, De Assumpção PP, et al. Investigation of Potentially Deleterious Alleles for Response to Cancer Treatment with 5-Fluorouracil. Anticancer Res. 2015;35:6971-7.

8. Väli U, Brandström M, Johansson M, Ellegren $\mathrm{H}$. Insertion-deletion polymorphisms (indels) as genetic markers in natural populations. BMC Genet. 2008;9:8.

9. Mullaney JM, Mills RE, Pittard WS, Devine SE. Small insertions and deletions (INDELs) in human genomes. Hum Mol Genet. 2010;19:R131-136.

10. He S, Yang S, Zhao Q, Wang L, Liu H, Sheng Y, et al. Association of IL4, IL6, and IL10 polymorphisms with pulmonary tuberculosis in a Tibetan Chinese population. Oncotarget. 2018;9:16418-26.

11. Abdalla AE, Lambert N, Duan X, Xie J. Interleukin-10 Family and Tuberculosis: An Old Story Renewed. Int J Biol Sci. 2016;12:710-7.

12. Yu Z-G, Wang B-Z, Li J, Ding Z-L, Wang K. Association between interleukin-17 genetic polymorphisms and tuberculosis susceptibility: an updated meta-analysis. Int J Tuberc Lung Dis. 2017;21:1307-13.

13. Mamtani M, Mummidi S, Ramsuran V, Pham M-H, Maldonado R, Begum K, et al. Influence of variations in CCL3L1 and CCR5 on tuberculosis in a northwestern Colombian population. $\mathrm{J}$ Infect Dis. 2011;203:1590-4.

14. Das S, Banerjee S, Majumder S, Chowdhury BP, Goswami A, Halder K, et al. Immune subversion by Mycobacterium tuberculosis through CCR5 mediated signaling: involvement of IL-10. PLoS One. 2014;9:e92477.

15. Kaewseekhao B, Naranbhai V, Roytrakul S, Namwat W, Paemanee A, Lulitanond V, et al. Comparative Proteomics of Activated THP-1 Cells Infected with Mycobacterium tuberculosis Identifies Putative Clearance Biomarkers for Tuberculosis Treatment. PLoS ONE. 2015;10:e0134168.

16. Chen R, Wang J, Tang S-W, Zhang Y, Lv X-Z, Wu S-S, et al. CYP7A1, BAAT and UGT1A1 polymorphisms and susceptibility to anti-tuberculosis drug-induced hepatotoxicity. Int $\mathrm{J}$ Tuberc Lung Dis. 2016;20:812-8.

17. Chang J-C, Liu EH, Lee C-N, Lin Y-C, Yu M-C, Bai K-J, et al. UGT1A1 polymorphisms associated with risk of induced liver disorders by anti-tuberculosis medications. Int J Tuberc Lung Dis. 2012;16:3768.

18. Yang B, Chen J, Li Y, Zhang J, Li D, Huang Z, et al. Association of polymorphisms in pre-miRNA with inflammatory biomarkers in rheumatoid arthritis in the Chinese Han population. Hum Immunol. 
2012;73:101-6.

19. Okubo M, Tahara T, Shibata T, Yamashita H, Nakamura M, Yoshioka D, et al. Association between common genetic variants in pre-microRNAs and gastric cancer risk in Japanese population. Helicobacter. 2010;15:524-31.

20. Cai T, Li J, An X, Yan N, Li D, Jiang Y, et al. Polymorphisms in MIR499A and MIR125A gene are associated with autoimmune thyroid diseases. Mol Cell Endocrinol. 2017;440:106-15.

21. Mullany LE, Herrick JS, Wolff RK, Slattery ML. Single nucleotide polymorphisms within MicroRNAs, MicroRNA targets, and MicroRNA biogenesis genes and their impact on colorectal cancer survival. Genes Chromosomes Cancer. 2017;56:285-95.

22. Liu X, Han Z, Yang C. Associations of microRNA single nucleotide polymorphisms and disease risk and pathophysiology. Clin Genet. 2017;92:235-42.

23. Zeng Y, Sun Q-M, Liu N-N, Dong G-H, Chen J, Yang L, et al. Correlation between pre-miR-146a C/G polymorphism and gastric cancer risk in Chinese population. World J Gastroenterol. 2010;16:357883.

24. Xu W, Xu J, Liu S, Chen B, Wang X, Li Y, et al. Effects of common polymorphisms rs11614913 in miR$196 a 2$ and rs2910164 in miR-146a on cancer susceptibility: a meta-analysis. PLoS ONE. 2011;6:e20471.

25. Morales S, Gulppi F, Gonzalez-Hormazabal P, Fernandez-Ramires R, Bravo T, Reyes JM, et al. Association of single nucleotide polymorphisms in Pre-miR-27a, Pre-miR-196a2, Pre-miR-423, miR608 and Pre-miR-618 with breast cancer susceptibility in a South American population. BMC Genet. 2016;17:109.

26. Zhang X, Li Y, Li X, Zhang W, Pan Z, Wu F, et al. Association of the miR-146a, miR-149, miR-196a2 and miR-499 polymorphisms with susceptibility to pulmonary tuberculosis in the Chinese Uygur, Kazak and Southern Han populations. BMC Infect Dis. 2015;15:41.

27. Naderi M, Hashemi M, Khorgami P, Koshki M, Ebrahimi M, Amininia S, et al. Lack of Association between miRNA-146a rs2910164 and miRNA-499 rs3746444 Gene Polymorphisms and Susceptibility to Pulmonary Tuberculosis. Int J Mol Cell Med. 2015;4:40-5.

28. Song X, Li S, QuCuo M, Zhou M, Zhou Y, Hu X, et al. Association between SNPs in microRNAmachinery genes and tuberculosis susceptibility in Chinese Tibetan population. Mol Biol Rep. 2013;40:6027-33.

29. Chen W-W, Wan B, Zhang R, Cao W, Liang L, Zhao Y-L, et al. Genetic Polymorphisms of miR-149 Associated with Susceptibility to Both Pulmonary and Extrapulmonary Tuberculosis. Genet Test Mol Biomarkers. 2019;23:442-7.

30. Yuan Y, Weidhaas JB. Functional microRNA binding site variants. Molecular Oncology. 2019;13:4-8.

31. Alemán-Ávila I, Cadena-Sandoval D, Morales MJ, Ramírez-Bello J. MicroRNA en enfermedades autoinmunes. Gac Med Mex. 2019;155:63-71.

32. Melo MC de, Barros H, Donalisio MR. Temporal trend of tuberculosis in Brazil. 2020. https://www.scielo.br/scielo.php?script=sci_arttext\&pid=S0102-311X2020000605009. Accessed 29 
Oct 2020.

33. Leal DF da VB, Santana da Silva MN, Fernandes DCR de O, Rodrigues JCG, Barros MC da C, Pinto PD do $\mathrm{C}$, et al. Amerindian genetic ancestry as a risk factor for tuberculosis in an amazonian population. PLoS One. 2020;15:e0236033.

34. Chimusa ER, Zaitlen N, Daya M, Möller M, van Helden PD, Mulder NJ, et al. Genome-wide association study of ancestry-specific TB risk in the South African Coloured population. Hum Mol Genet. 2014;23:796-809.

35. Daya M, van der Merwe L, van Helden PD, Möller M, Hoal EG. The role of ancestry in TB susceptibility of an admixed South African population. Tuberculosis. 2014;94:413-20.

36. Dye C, Scheele S, Dolin P, Pathania V, Raviglione MC. Consensus statement. Global burden of tuberculosis: estimated incidence, prevalence, and mortality by country. WHO Global Surveillance and Monitoring Project. JAMA. 1999;282:677-86.

37. Ge H-B, Chen S. A meta-analysis of P2X7 gene-1513A/C polymorphism and pulmonary tuberculosis susceptibility. Hum Immunol. 2016;77:126-30.

38. Stead WW, Senner JW, Reddick WT, Lofgren JP. Racial differences in susceptibility to infection by Mycobacterium tuberculosis. N Engl J Med. 1990;322:422-7.

39. Sambrook J, Fritsch EF, Maniatis T. Molecular cloning: a laboratory manual. USA: Cold Spring Harbor Laboratory Press; 1989.

40. Ramos BR de A, D’Elia MPB, Amador MAT, Santos NPC, Santos SEB, da Cruz Castelli E, et al. Neither self-reported ethnicity nor declared family origin are reliable indicators of genomic ancestry. Genetica. 2016;144:259-65.

41. Santos NPC, Ribeiro-Rodrigues EM, Ribeiro-Dos-Santos AKC, Pereira R, Gusmão L, Amorim A, et al. Assessing individual interethnic admixture and population substructure using a 48-insertion-deletion (INSEL) ancestry-informative marker (AIM) panel. Hum Mutat. 2010;31:184-90.

42. Pritchard JK, Stephens M, Donnelly P. Inference of population structure using multilocus genotype data. Genetics. 2000;155:945-59.

43. Falush D, Stephens M, Pritchard JK. Inference of population structure using multilocus genotype data: linked loci and correlated allele frequencies. Genetics. 2003;164:1567-87.

44. FALUSH D, STEPHENS M, PRITCHARD JK. Inference of population structure using multilocus genotype data: dominant markers and null alleles. Mol Ecol Notes. 2007;7:574-8.

45. San Pedro A, Oliveira RM de. [Tuberculosis and socioeconomic indicators: systematic review of the literature]. Rev Panam Salud Publica. 2013;33:294-301.

46. Migliori GB, Garcia-Basteiro AL. Predicting the effect of improved socioeconomic health determinants on the tuberculosis epidemic. Lancet Glob Health. 2018;6:e475-6.

47. Aravindan P. Host genetics and tuberculosis: Theory of genetic polymorphism and tuberculosis. Lung India. 2019;36:244-52. 
48. Bernstein KE, Khan Z, Giani JF, Cao D-Y, Bernstein EA, Shen XZ. Angiotensin-converting enzyme in innate and adaptive immunity. Nat Rev Nephrol. 2018;14:325-36.

49. Gamazon ER, Segrè AV, van de Bunt M, Wen X, Xi HS, Hormozdiari F, et al. Using an atlas of gene regulation across 44 human tissues to inform complex disease- and trait-associated variation. Nat Genet. 2018;50:956-67.

50. Ferreira PG, Muñoz-Aguirre M, Reverter F, Sá Godinho CP, Sousa A, Amadoz A, et al. The effects of death and post-mortem cold ischemia on human tissue transcriptomes. Nat Commun. 2018;9:490.

51. Xie Y, You C, Chen J. An updated meta-analysis on association between angiotensin I-converting enzyme gene insertion/deletion polymorphism and cancer risk. Tumour Biol. 2014;35:6567-79.

52. Guerra FE, Borgogna TR, Patel DM, Sward EW, Voyich JM. Epic Immune Battles of History: Neutrophils vs. Staphylococcus aureus. Front Cell Infect Microbiol. 2017;7:286.

53. Bernstein KE, Khan Z, Giani JF, Zhao T, Eriguchi M, Bernstein EA, et al. Overexpression of angiotensinconverting enzyme in myelomonocytic cells enhances the immune response. F1000Res. 2016;5.

54. Zmorzynski S, Szudy-Szczyrek A, Popek-Marciniec S, Korszen-Pilecka I, Wojcierowska-Litwin M, Luterek M, et al. ACE Insertion/Deletion Polymorphism (rs4646994) Is Associated With the Increased Risk of Multiple Myeloma. Front Oncol. 2019;9. doi:10.3389/fonc.2019.00044.

55. Marques D, Ferreira-Costa LR, Ferreira-Costa LL, Correa R da S, Borges AMP, Ito FR, et al. Association of insertion-deletions polymorphisms with colorectal cancer risk and clinical features. World Journal of Gastroenterology. 2017;23:6854-67.

56. Gemmati D, Tisato V. Genetic Hypothesis and Pharmacogenetics Side of Renin-Angiotensin-System in COVID-19. Genes (Basel). 2020;11.

57. Sarangarajan R, Winn R, Kiebish MA, Bountra C, Granger E, Narain NR. Ethnic Prevalence of Angiotensin-Converting Enzyme Deletion (D) Polymorphism and COVID-19 Risk: Rationale for Use of Angiotensin-Converting Enzyme Inhibitors/Angiotensin Receptor Blockers. J Racial and Ethnic Health Disparities. 2020. doi:10.1007/s40615-020-00853-0.

58. Gómez J, Albaiceta GM, García-Clemente M, López-Larrea C, Amado-Rodríguez L, Lopez-Alonso I, et al. Angiotensin-converting enzymes (ACE, ACE2) gene variants and COVID-19 outcome. Gene. 2020;762:145102.

59. Ogarkov OB, Sin’kov VV, Medvedeva TV, Gutnikova MI, Nekipelov OM, Raevskaia LI, et al. [Polymorphism of genes of the renin-angiotensin system ACE, AT1R, and AT2R in patients with pulmonary tuberculosis]. Mol Gen Mikrobiol Virusol. 2008;:12-8.

\section{Supplementary Files}

This is a list of supplementary files associated with this preprint. Click to download.

- Additionalfile1.docx 